\title{
ACRL develops leaders in New York
}

\section{Highlights of ACRL programs at ALA's 1996 Annual Conference}

$\boldsymbol{A}$

CRL members sampled the best of the Big Apple during ALA's 115th Annual Conference in July. Total conference attendance was 23,747 members, exhibitors, and guests, including 10,812 paid registrants-which falls below the record high set in Chicago last year (13,290 paid, 24,653 total). This conference offered the innovative "conference-within-a-conference" featuring three programs on ACRL president Patricia Senn Breivik's theme, "Every Librarian a Leader," and many more exploring the topic of leadership. Highlights of the programs are below. ( $E d$ note: Thanks to the many members who summarized programs for CERL News so we could bring you this report.)

\section{ACRL President's Program: Every Librarian a Leader}

We knew this was a different ACRL program when we entered the huge room in Javits and were handed a 50+-page purple workbook, a yellow visor (Every Librarian a Leader), and a program spanning three days.

After president Patricia Breivik's warm welcome and program chair Deborah Leather's brief introductions, Dadie Perlov (founder and principal of Consensus Management Group) ignited the session with boundless energy and inspiration. Telling the nearly packed room that hers would not be the typical keynote address, she involved the audience by debunking several myths about leadership (e.g., leaders always have high-status positions); clarified the many characteristics of leaders; described several future

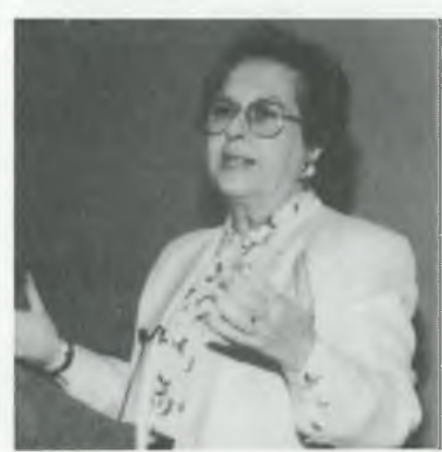

Dadie Perlov debunks myths about leadership. trends affecting libraries; and illustrated the relationships between leadership styles and life cycles of organizations.

Offering a simple definition of leadershipa leader is someone who will take you to a place you wouldn't go without him or her-she stressed that leaders are not born, but made. Drawing on Kouzes and Posner's The Leadership Challenge (1990), Perlov emphasized these key characteristics: leaders challenge the process, bypassing bureaucracy and always asking why; they inspire a shared vision; they ban killer statements such as "It's not in the budget"; and they make assumptions about the future.

Among the future trends affecting libraries and librarians is a double-barreled one new to this attendee: disintermediation, which refers to the breaking down of delivery systems from producers to consumers and its reverse, remediation, or the rediscovery that people need someone between the producer and the consumer. Using the Internet as an example, she pointed out librarians' critical leadership role as "remediators."

Even though the audience was huge, Perlov used three interactive exercises to involve us, including a case study that challenged us to apply some of the concepts and issues presented. I heard several colleagues remark about how similar the case issues were to those at their institutions.

Enthusiastic, dynamic, funny, gutsy, and spirited are all words to describe Perlov's presentation style and content as she modeled the leadership characteristics discussed. Comforting to all of us were her summary comments that included: there is no one best style of leadership and there is no recipe or template for leadership; it comes from practice by trial and error and learning from success and fail- 


\section{Unleashing the power of flexible thinking}

The second session of the ACRL President's Program featured Manny Elkind (Consensus Management Group) as the facilitator.

Elkind stimulated a responsive audience for the three-hour program into a participatory look at the way people think. He led the way for everyone to learn how individuals can change perspectives to avoid getting stuck and to find ways to improve communication and relationships. As Elkind revealed, this is one of the vital issues in leadership.

Building on the previous opening session, and through discussion and exercises, he introduced the concept of the Whole Brain Model, which profiles thinking preferences: the four quadrants are FACTS, FORM, FUTURES, and FEELINGS, which evolve into RATIONAL SELF, SAFEKEEPING SELF, EXPERIMENTAL SELF, and FEELING SELF. Each quadrant is associated with a color that identifies a type of thinking and the participants identified themselves as one or two of the types and became color-conscious. By understanding one's own brain process and what colors each part is, then understanding that others have different models, individuals were on the way to communicating and learning with more flexibility. Leadership evolves from understanding how different modes of perception and decision-making can help produce a more effective organization. As leaders, we can establish rapport with others, sell our ideas, solve problems, and enjoy what we are doing using the lessons learned here.

None of these concepts are static; thinking preferences change with life changes and with physiological changes. There is interaction between the brain and the body. Inconsistency is part of life, and individuals' behavior may not reflect what is expected from the model. Flexibility is a key factor in leadership. The leader must be able to step into another person's culture with understanding and acceptance.

With humor, wonderful examples, exercises that made the participants look at themselves and think about thinking, Elkind left the audience with new understanding on how the Whole Brain Model works, and with an appre- ciation of using this model in preparing for leadership.-Ferne B. Hyman, Rice University

\section{Creating your future}

The President's Program concluded with a third session in which each participant was given an opportunity to assess his or her leadership style as defined by the four categories presented in session two. Dadie Perlov opened the session by stressing the importance of librarians assuming leadership roles in the "Information Age." She cited the failure of American railroad companies to assume a leadership role in transportation as an example of what can happen when a group is bypassed by technology and/or social change.

participants were asked to conduct personal leadership inventories in which they identified their most important leadership achievements. Participants then reviewed the criteria used to determine the relative importance of different accomplishments and the role each individual had played in his or her achievement. Real leadership results when individuals internalize the goals and objectives of a project. Leadership is creating the environment in which the members of a group can accomplish desired ends.

The session ended with a discussion of "Organizational traps," forces that undermine the ability of a group to function as a unit or to direct its energies in a particular cirection: 1) the we/they syndrome, 2) lack of motivation and accountability, 3) democracy (lack of consensus on decisions), 4) conflict, and 5) overload and burnout.

The overall message of the program was that one has to understand the framework from which various individuals view the world in order to maximize their integration into an effective organization. Leadership is the ability 
to identify individuals' areas of strength and potential and to draw upon these to support the efforts of an organization. Leadership can be exercised from the top, middle, or even bottom of the organization.-Stanton F. Biddle, Baruch College, City University of New York

\section{Librarians tour Black Culfure Library}

The tour of the Schomburg Center for Research in Black Culture at the New York Public Library was sponsored by ACRL's Afro-American Studies Librarians Section (AFAS), the Black Caucus of ALA (BCALA), and the New York Black Librarians Caucus.

The tour, conducted by the staff of the Research Center, consisted of visits to the General Research and Reference Collection with holdings of 125,000 volumes, 85,000 microforms, 400 black newspapers, and 6,000 serials from around the world. The tour then proceeded through the remaining four special collections of primary resources: 1) Manuscripts, Archives, and Rare Books, 2) Arts and Artifacts, 3) Photographs and Prints, and 4) Imaging and Recorded Sound. Viewers were shown a short film created by the Imaging Division on the history of the Schomburg Center emphasizing the contributions of Auturo Alfonso Schomburg. James Briggs Murray, the narrator of the film and curator, discussed the process of digitizing the collection to make it accessible to a wider audience in the technological age.

Time was spent accessing the digitized collection via the Internet and the World Wide Web and receiving an introduction to the BCALA homepage constructed by Rochelle Ballard (University of Central Florida) and Jon Cawthorne (University of Oregon).

Viewers visited the current exhibit, "The Schomburg Legacy-Documenting the Global Black Experience for the 21st Century," which is a selection of items in various media from the center's collections that document a range of issues and themes in the historical and cultural development of African people worldwide.

In the program following the tour, AFAS gave memorial tributes to two outstanding African American librarians: Gladys Smiley Bell (Kent State University) profiled Dorothy Burnett Porter Wesley and Michael C. Walker (Virginia Commonwealth University) profiled Doris Hargrett Clack. Then Stanton Biddle (Baruch College, CUNY, and BCALA chair) presented to the Schomburg Research Center Culture Keepers and Culture Keepers $I I$, the published and taped proceedings that document the first and second National Conferences of African American Librarians.-Bennie P. Robinson, University of Akron

\section{The intersection of archives, libraries, and museums}

In "Anthropological Documentation and Research in the New York Area: The Intersection of Archives, Libraries, and Museums," Barbara Mathe (Metropolitan Museum of Art) reinforced most effectively not only the interdisciplinary and cross-cultural theme of the Anthropology and Sociology Section (ANSS) program, but the leadership focus of the ACRL program as well. She exhorted librarians to be leaders who continue to learn about the subjects of their collections and formulate answers to questions that haven't even been asked. Mathe's discussion revolved around various approaches to the arts of Africa, Oceania, and the Americas, ranging from art as material culture to art as aesthetic object, and how these approaches are reflected in the literature about these arts.

Mathe was one of three participants to speak about the relationship between museums and libraries. I)eirdre Lawrence (Brooklyn Museum Library) provided valuable insights into the limitations of documentation surrounding most systematic ethnographic collections by contrasting research collections on art and ethnography of the Americas assembled by Stewart Culin and Herbert J. Spinden, two curators at the Museum between 1903 and 1950 . Valerie Wheat (American Museum of Natural History Library) discussed the challenges that museum libraries face as their role within the museum continues to be redefined

The Human Relations Area Files (HRAF), founded in 1949 at Yale University, facilitate the comparative study of human society by collecting and organizing ethnographic materials, among them works published under the auspices of research museums. Melvin Ember (president of HRAF) shared with the audience exciting plans for expanding and improving HRAF in the near future by updating the ethnographic database, adding a prehistory database, and improving sampling procedures. Maija M. Lutz, Hariard University

\section{The electronic horizon for the college library}

With tight budgets, how can college libraries close the resource gap with larger university 
libraries? And how can college librarians become leaders in the technological revolution? New technologies for electronic journal publication may provide the means. In "The Electronic Horizon for the College Library: Electronic Journals and Other New Technologies," sponsored by the College Libraries Section, three projects funded by the Mellon Foundation were featured.

Moderator Neil McElroy (Lafayette College) introduced Rick Eckman (Mellon Foundation), who described his foundation's interest in promoting these pilot projects in order to help college libraries stretch their dollars. Eckman explained that JSTOR, a cooperative effort launched by Mellon, stores electronically the pre-1990 issues of 10 core journals in economics and history, linking a search engine to bitmapped text. Connie Dowell (Connecticut College) and Willis Bridegam (Amherst College) told how they had negotiated a group discount for some 60 members of the Oberlin Group-a consortium of college libraries-to become charter subscribers to Project Muse, a Mellon-funded project that provides Web access to the journals

\section{PROVE YOUR POINT}

\section{Invest in your collection with OCLC/AMIGOS Collection Analysis Systems.}

Ask for a FREE Collection Analysis CD demo set for results you can see!

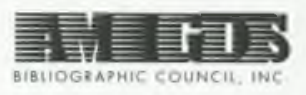

amigos@amigos.org ～800/843-8482２14/851-8000 published by the Johns Hopkins University Press using nonproprietary client-server software (Mosaic) and the Internet infrastructure.

Richard Meyer (Trinity University, Texas) discussed development of the third Mellonsponsored effort, the Palladian Alliance, which brings campuswide access to the full text of journals throughout the Associated Colleges of the Midwest through a consortial subscription to FirstSearch, including the UMI indexes and the full text of journal articles in ASCII format.

All the speakers emphasized the importance of consortial cooperation in creating and providing lower-cost electronic access. In his response, Paul Gherman (Vanderbilt University) raised a series of questions. Will electronic publication increase or decrease the monopoly power of journal publishers? Will it be there in the future? Will each publisher have a different front end? How will past subscriptions be tracked for archiving? Who will pay for refreshing electronically stored information? Will all journals be available under the most recent software? How will copyright be tracked? How will we access information we have not bought? And how will archives be coordinated?Damon D. Hickey, The College of Wooster

\section{Leadership on the cybercampus commons}

In the Extended Campus Library Services Section/Community and Junior College Libraries Section collaborative contribution to this year's ACRL theme of "Every Librarian a Leader," "Leadership on the Cybercampus Commons: Where Are We in the Vision?" three senior academic officers described their institutions' use of information technology in reaching out to all students, and discussed questions about leadership in overcoming limitations of time and place. Progress depends on a whole new way of thinking- "looking outside the box"-for new strategies to approach current needs. Speakers were James Hall (Empire State Uni- 

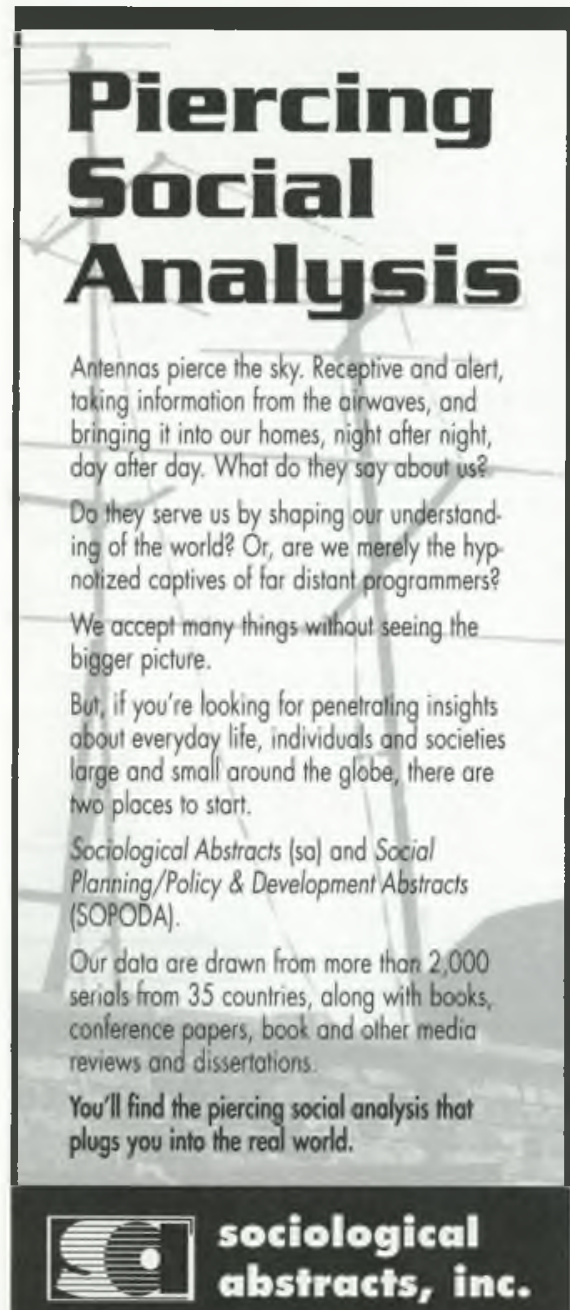

\section{P.O. Box 22206, Son Diego, CA 92192.0206} 619/695.8803, Fox: 695.0416

Internet; socio@cerfnet.com

User Assistonce: 800/752.3945

Serving the sociological community since 1953

The SAI family of serivces: Sociological Abstracts (SA) - Social Planning/Pollcy \& Development Abstrocts (SOPODA] * sociofile (SA and SOPODA on CD-ROM). Products are available in print; online from Knight-Ridder, DIMDI, OCLC, and Ovid; on CD-ROM from SilverPlatter, EBSCO and Ovid; on magnetic tape vio SAl direct. versity); Richard Skinner (Clayton State College); and Gilbert Gonzalez (Mesa State College).

Questions from moderator Nancy Allen (University of Denver) included: What has changed about your campus environment's need for leadership? What are some common themes in the different settings? What, if anything, needs to be changed about the library community on the cybercampus? and What is in place to reeducate faculty who have not recognized new ways of doing business? A central idea involved a student-centered convergence of resources, offering a multiplicity of ways to learn. The teacher/mentor becomes an intellectual coach, or a rudder to keep each student on course, probably using e-mail for asynchronous communication.

The immense financial cost of information technology was acknowledged: for it to be adequate it must be pervasive in order to reach the critical mass and to provide a level playing field. Much more support is needed for personnel - the "human infrastructure" - to learn their new roles. The student-centered focus will demand a leap to another dimension in our already strong service ethic in order to give every learner the attention and service made possible by high-quality connectivity.

Funding will depend on forging new partnerships, creating new revenue streams, and linking diverse organizations that are data and information rich. To move ahead in the best way possible, the profession will need risk-taking individuals with vision and foresight who are open to new ideas "from outside the academy," and who credit the ideas of those who implement the programs. The reality will not be a wholesale movement from the old models to the new, but will be a shift toward including the new with the old, incorporating all learning options to provide a path for lifelong learning.-Laura Bottoms, Rogers State College, and Betsy Hine, Indiana State University

\section{Political campaigning in cyberspace}

The Law and Political Science Section (LPSS) program, "Political Campaigning in Cyberspace: Selecting Leaders for the Future," focused on Web sites offering voting and campaign information. Adelaide B. Elm (Project Vote Smart) was featured, and the section unveiled its program Web page.

Elm showed a Project Vote Smart videotaped public service announcement with actor Edward James Olmos and asked the audience to 
think about politics and election campaigns as they are conducted today: what would have happened if Thomas Jefferson had written the Constitution on a personal computer, and the reactions of people like Jefferson to the quality of information available to voters today.

Elm then explained how most people feel about this quality by citing a recent League of Women Voters poll in which $57 \%$ of nonvoters would rather work overtime for extra money than vote and $30 \%$ would rather shop sales. In another poll, $55 \%$ of nonvoters and $60 \%$ of voters feel there is not enough information to make an informed vote.

Many people, she added, feel this way because of the kind of advertisements used by candiclates. She showed a video montage of political campaign ads from the 1950 s to the late 1980s. These included an ad created in 1988 by supporters of Arizona Senatorial candidate Richard Kimball against incumbent John McCain. Kimball, who lost this election, decided there needed to be a nonpartisan group to let voters know how candidates really feel about issues rather than being subjected to visions of candidates as created by pollsters, spin doctors, and the candidates themselves. Thus the Center for National Independence in Politics and Project Vote Smart were born.

The Project began its trial run in 1990 , providing resumes of candidates, voting, and biographical information of those running for office. The key to these reports, "The National Political Awareness Test" [NPAT], was developed to provide the public with unbiased information on politicians running for office. The Project obtained funding to provide its services to all 50 states in 1992 and a Voters Research Hotline was established.

Information is available to voters through a toll-free 800 number which allows people access to three minutes of information on how the candidates feel about different issues. Elm relayed one humorous incident in which one caller, who turned out to be a wanted fugitive, asked if he could be arrested if he came out of hiding to vote. In 1990 the national media overwhelmed the system while seeking information on the candidates. So the Project created an online database especially designed for access by the national media and issues briefs which are free to journalists and available to the public for a small cost.
In mentioning the Project's Web page, Elm noted that although only $3 \%$ of the total public, or 1 in 5 computer users, have accessed the Web, the number of people wanting candidate information is growing. The Project's Web site can provide a variety of information on candidates and the issues, including legislation status tracking on a daily basis. Elm noted that the only stipulation is that the organization would love to be credited for being the source of the information.

Jan Lewis (Virginia Commonwealth University), a member of the LPSS Library Instruction Committee, demonstrated the section's Web program page. Each section of the site was done by a different member of the committee and includes Web sites for political parties, primaries and conventions, Presidential candidates and issues, state and local candidates, nonpartisan groups, news coverage and analysis, and

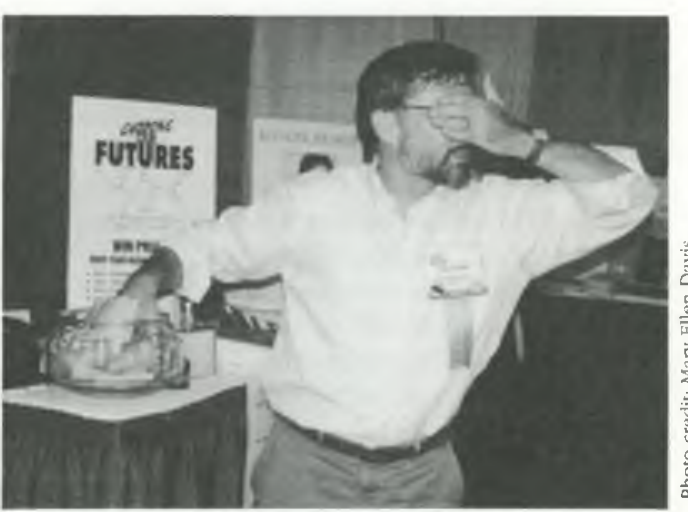

Paul Coleman of West Texas A\&M University pulls the name of the winner of an ACRL baseball cap.

scholarly discussion lists and electronic conferences. (Ed. note: see pages $000-00$ for the Internet resource list developed as a companion to the program.)

In closing, Elm said the Vote Smart Web Yellow Pages will be available for the public beginning in August. To receive a free copy of the Voter's Self Defense Manual or the Vote Smart Web Guide, you can call (541) 754-2746. - Brian $B$. Carpenter, Texas AEM University

\section{Instructional models for Internet training}

In "Instructional Models for Internet Training: Teaching Trainers Who Teach Library Users," sponsored by the Professional Education Committee, speakers from a variety of academic set- 
tings described several approaches to training. Common themes included: combining computer literacy instruction with the earliest Internet classes; the need for rapid development of training sessions as new technologies appear; training nonlibrarians, including student peers, to provide Internet training; and cooperating closely with the campus computing center.

Lorelei Tanji described the six different training models used at the University of California, Irvine. In the fast-rack model, trainers included library staff, graduate students, or academic computing personnel-anyone with the expertise to provide as-needed training sessions. (Information on the other models can be found at http://sun3.lib.uci.edu/ ltanji/pec.htm.)

Mary Jane Petrowski (Colgate University) described her experiences at a small, private liberal arts institution. For one faculty/staff development program, collaboration among campus units, including the libraries, resulted in the creation of a clearinghouse of training material that could be used by any trainer needing to teach on a given topic. In another cooperative effort, librarians worked closely with faculty to design curricula with meaningful research components. This was an opportunity to teach faculty to see themselves as "networked information resources" trainers, a role with which they may have been unfamiliar.

Betsy Wilson (University of Washington) described her university's Uwired project, a collaboration of librarians, professors, and com- puter professionals to integrate "electronic communication and information navigation skills into instruction and learning." Wilson emphasized the importance of integrating Internet skill training into staff development, focussing on good teaching and providing training at the time of need so that it can be reinforced via immediate application. (Further information about the project can be found at http://www.cac. washington.edu/uwired/uwired.html.)—Richard Sapon-White, Oregon State University

\section{Beyond the library book sale}

The Rare Books and Manuscripts Section program, "Beyond the Library Book Sale: Leading the Way into the Marketplace," addressed issues for libraries trying to forge relationships that are beneficial for economic progress. Speakers showed how special collections could be marketed and made available to a variety of users, without losing sight of the fundamental principles of librarianship.

Sally Leach (Harry Ransom Humanities Research Center at the University of Texas at Austin) spoke on "Walking the Fine Line" between the scholarly and commercial values of collec tions. Her strongest recommendation was to obtain advice from institutional legal council, literary agents, and other librarians before plunging into the world of publishing, licensing, and promotional agreements. She suggested exploring thoroughly the library's rights and responsibilities "before, rather than after, selling

\section{Order your Annual Conference audiocassettes}

Audiocassettes of selected ACRL programs from the 1996 ALA Annual Conference in New York are now available. Each program consists of two cassettes and sells for $\$ 24.00$, unless otherwise noted.

Leadership on the Cybercampus Commons: Where Are We in the Vision? 1 cassette, $\$ 12.00$. Order no. ALA 603

ACRL President's Program: Every Librarian a Leader. Order no. ALA 605

Anthropological Documentation \& Research in the New York Area: The Intersection of Archives, Libraries \& Museums. Order no. ALA 611

Collaborative Solutions to Technostress: Libraries Lead the Way. Order no. ALA 634
From Unit Manager to Team Captain: Leadership Skills in the Re-engineered Library. Order no. ALA 618

That's Not What I Was Hired to Do: The Future of Your Career and Your Career in the Future. 1 cassette, $\$ 12.00$. Orcler no. ALA 628

Beyond the Library Book Sale: Leading the Way Into the Marketplace. Order no. ALA 647

Audiocassettes for other programs are also available. Call, write, or fax your order or a request for an order form to: Teach'em, 160 E. Illinois St., Suite 300, Chicago, IL 60611; (312) 467-0424; fax: (312) 467-9271 or (800) 225-3775. You may pay by check (payable to Teachem) or credit card (VISA, MC, AMEX). 
the farm." She also stressed the need to have written guidelines and agreements for the publishing and use of materials. Overall, her advice for proceeding into marketing special collections was to negotiate for fairness, learn the art of consensus and compromise, and know the collection well enough to determine what materials are best suited to this use.

Robert Ritchie (Huntington Library) spoke on "Selling Images: The Experience of One Institution." He stated that his experiences can be applied to all institutions with visual holdings, since demand for such items is increasing and more requests for use are being received from nontypical users. He recounted the decision to use a stockhouse that was already in the business of marketing images and had guidelines in place for many legalities and the staff to provide quality images quickly. The need for retaining control over images was emphasized, as was the need to ask questions of patrons in order to determine how these images were to be used. Ritchie also recommended formulating contracts that cover areas of concern and developing negotiable fee structures,Katherine Fox, University of Houston

\section{Accessing library/archive collections in Russia and Eastern Europe}

Scholars from various disciplines are finding valuable materials in the libraries of Russia and Eastern Europe. Speakers at the Slavic and East European Section program, "New Audiences, New Perspectives: The Role of the Slavic and East European Specialist in Support of NonSlavic and East European Studies," described projects aimed at using, documenting, and preserving these collections.

Myra D. Orth (Getty Center, emerita) participated in a Getty Center project that microfilmed illuminated manuscripts of the Academy of Sciences Library in St. Petershurg and the National Museum in Prague. Each of the reproductions was planned by an archivist. The institutions involved received negatives and microfilm copies of the originals.

David E. Fishman (Jewish Theological Seminary, YIVO) pointed out that some types of materials have not been available in the West. Several projects aimed at improving access to this material are under way, including Project Judaica, which trains specialists in Russia to care for archival materials.

Elizabeth A. R. Brown (Brooklyn College, emerita), described how training provided through IREX (the International Research and Exchanges Board) enhanced the success of her research at the Saltykov-Shchedrin Public Library, which houses an extensive collection of medieval manuscripts. IREX trained Brown to use the library and introduced her to Russianspeaking colleagues. Brown wondered how other scholars could receive similar assistance. Discussant Robert A. Karlowich (Pratt Institute) reiterated this problem and emphasized the need to unite scholars with resources. He suggested that the Internet might be one way of gathering and updating information.-Julie Swann, University of Nebraska-Lincoln

\section{The changing face of European studies}

Concern for the "Changing Face of European Stuclies" and what it portends for collection development was the focus of a program sponsored by the Western European Specialists Section and the Slavic and East European Section. Leena Siegelbaum (Michigan State University) noted that until recently "Europe was stable, predictable, and boring." Now, since the end of the Cold War, researchers are demonstrating renewed interest in the area. But, as moderator Martha Brogan (Yale University) pointed out, their investigations are becoming increasingly problem-oriented, centering less on specific geographic locations than on border-crossing issues such as migration, multiculturalism, and the diminished role of government. Siegelbaum suggested that collecting for this kind of research may require more cooperative planning among libraries in order to build comprehensive collections.

An example of international cooperation was provided by Marcelino Ugalde (University of Nevada-Reno), who described his library's unique collection and his collaboration with institutions in the Basque countries. A project to produce a CD-ROM index of seven daily newspapers is under way there.

The utility of making research materials accessible electronically was emphasized by David Magier (Columbia University). Calling the Internet a "great library, but one where the patrons add the books and decide where they shelve," he stressed the importance of access by subject, and advised that bibliographers should concentrate on evaluation and annotation of Web sites, while others could be responsible for more technical tasks. - Nancy Boemer, Indiana University-Bloomington 


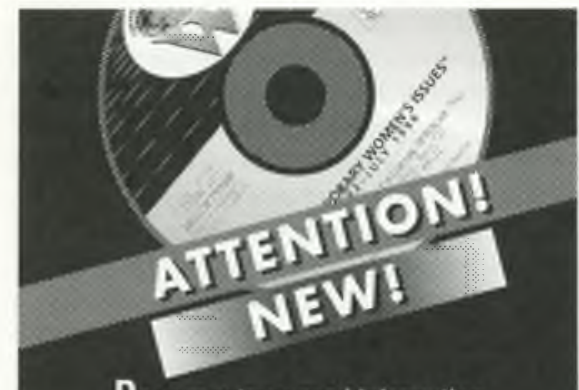

Do your patrons need information

on women's issues such as adoption. pay equity, eating disorders,

lesbian concerns, sexual harassment, reproductive health $\&$ rights, domestic violence issues. menopause and more? Then... CONTEMPORARY WOMEN'S ISSUESTM will be a welcomed addition to your collection.

.........

CONTEMPORARY WOMEN'S ISSUESTM

Is an easy to use full-text CD-ROM database covering diverse issues that affect women's daily lives

\section{Is compiled from over 600 publications}

Includes hard-to-find reports, pamphlets. guides, fact sheets, and journal \& newsletter articles

Addresses issues from local, national, and international perspectives

Priced at only $\$ 600$ for an annual subscription Network pricing available

Discounts for developing nations and high schools ........

Provide your patrons with this unique. new source that will bring them the answers they need now.

Order a FREE PREVIEW CD-ROM

Call RDS at 1-800-313-2212 (USA and Canada)

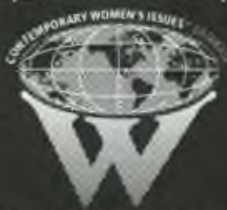

\section{CONTEMPORARY WOMEN'S ISSUES}

AN RDS SERVICE

23511 CHAGRIN BLVD SUITE 320

BEACHWOOO OH A4122 USA

TEL 216-292-9620 - FAX 2:5-292-96?1

E-MAll cuitomer iersiceardsicec.com
Librarians develop women's studies electronic resources

Since the inception of women's studies as a discipline, accessing the published literature has been a constant problem. The program "Leadership and Collaboration: Librarians Develop Women's Studies Electronic Resources," sponsored by the Women's Studies Section, the AfroAmerican Studies Section, the ALA Committee on the Status of Women in Librarianship, and the Social Responsibilities Round Table Feminist Task Force, provided some solutions.

The existing obstacles to accessing the published literature are due in part to 1) poor representation of resources in the various inclexes and databases, 2) inadequate subject headings, and 3) complex search strategies. Although the change in format of the public catalog and indexes has contributed positively to accessibility, the problem still persists.

In her presentation, "Fantasies, Foibles, and Facts: Promoting Women's Studies Online," Phyllis Weishard (Wisconsin Library System) encouraged librarians to publish full-length bibliographies and full-text articles directly on the Web, and to encourage CD-ROM vendors to cover a broader range of women's studies resources and simplify search strategies.

Gladys Smiley Bell (Kent State University) demonstrated online how to use various Internet indexes to identify resources on womenAfrican American women in particular-and how to create links to homepages to enhance access in spite of no specificity capability to lock out irrelevant resources. The lack of specificity capability in searching the Net using either of the various search engines is a challenge to vendors to refine their products.

The construction of a database is difficult. It requires negotiating with publishers concerning who owns what, converting and digitizing the printed word, securing the appropriate software platform, and effectively indexing the various works with the help of librarians. Ralph Ferragamo (Softlink, Inc.) discussed a new product called "Women R," a full-text database for women's studies that has two unique features: the ability to rank sources according to relevancy within the search results and the ability to consult a directory for various publishers of resources contained in the database. Librarians, vendors, and publishers working together, each doing what they do best, can enhance the accessibility of women's studies resources.Bennie P. Robinson, University of Akron 


\section{Perception \& Reality}

\section{Perception}

Any vendor can provide adequate coverage of English language titles.

\section{Perception}

All approval vendors provide the same level of bibliographic expertise.

\section{Perception}

Traditional bibliographic resources are sufficient to manage a library's needs.

\section{Reality}

Blackwell's unified US \& UK buying provides comprehensive approval coverage of English language scholarly publications.

\section{Reality}

Blackwell's professional bibliographers deliver a consistently higher level of bibliographic control for the entire range of English language titles.

\section{Reality}

Blackwell pioneered coordinated US \& UK Internet/Web accessible tools providing better resources to meet the needs of modern libraries.

\section{Blackwell's Preferred Edition provides the REALITY of complete English language approval services.}

Second in a series from BLACKWELL 